\title{
A Study of Pituitary Adenoma Surgery: Transphenoidal Microscopic Versus Endoscopic Endonasal Approach
}

\author{
HARADHAN DEB NATH ${ }^{1}$, KANAK KANTI BARUA ${ }^{2}$, KAZI HAFIZ UDDIN ${ }^{3}$, MONIRUL ISLAM $^{3}$, OMAR \\ FARUQUE ${ }^{3}$, ATIQUR RAHMAN $^{3}$, SHAHNEWAZ BARI $^{3}$, RAHUL QUDDUS $^{3}$
}

\begin{abstract}
:
Background: Transphenoidal endoscopic approach is minimal invasive surgery in case of pituitary adenoma. Objective : To see the outcome of transphenoidal endoscopic and microscopic approach in case of pituitary tumor. Results : This study showed among the 37 patients, 25 (67.6\%) were done by transphenoidal microscopic approach and 12 (32.4\%) patients were done by endonasal endoscopic approach. Among the 12 patients $8(66.7 \%)$ were male and 4(33.3\%) were female. Among the 25, patients $15(60 \%)$ were male and 10(40\%) were female. It was documented that in 12 patients, $10(83.3 \%)$ were macroadenoma and $2(16.7 \%)$ were microadenoma. It was evident that among the 25 patient 18(72\%) were macroadenoma and 7(28\%) were microadenoma. Among 12 patients, 11 (91.7\%) had preoperative visual disturbance and $1(8.3 \%)$ had normal vision. It was observed that among 25 patients, 23(92\%) patients had preoperative visual disturbance and 2 (8\%) patients had normal vision. Tumor was totally removed in 9(75\%) patients in endoscopic approach and 14(56\%) in microscopic approach. Clinically 10(83.3\%) patients were improved in endoscopically and $16(64 \%)$ patients were improved in microscopic group. Conclusion: It was concluded that endoscopic endonasal approach is better than transphenoidal microscopic approach.
\end{abstract}

Key word: Pituitary adenoma, transphenoidal approach, endoscopic endonasal approach, microscopic approach, acromegally, cushing's syndrome.

Introduction:

Pituitary adenomas are the third most common intracranial neoplasm, accounting for $10 \%-25 \%$ of intracranial neoplasms with a prevalence of $16.9 \%$ in autopsy studies ${ }^{1}$.

In March 1907, Schloffer reported the first successful removal of a pituitary tumor via a superior nasal transsphenoidal approach, which was based on Giordano's experimental work ${ }^{2}$. The sublabial transsphenoidal route to the sella turcica, originally pioneered by Harvey Cushing ${ }^{3}$.

In 1967, Hardy introduced the use of the operating microscope for this procedure and developed and designed his own microsurgical instrumentation, which transformed transsphenoidal surgery. The excellent visualization and surgical results provided by the endoscope in sinus surgery have prompted neurosurgeons to explore its potential application to transsphenoidal surgery ${ }^{4}$.

The endonasal microscopic transsphenoidal approach has several variations, including the transseptal submucosal technique, the septal pushover and the direct sphenoidotomy ${ }^{5}$.

Authors reported the first use of the endoscope in pituitary surgery in 1978 but its application to the sella turcica did not grow in popularity, however, until the mid-1990s, when endoscopic sinus surgery had virtually replaced conventional open techniques in use by otolaryngologists for the treatment of inflammatory sinonasal disorders. Many modifications of the transsphenoidal approach have been developed; they range from sublabial transnasal, transnasal, and pure endonasal endoscopic approaches and are used with an

1. Associate Professor, Department of Neurology, BSMMU, Dhaka

2. Professor and Chiarman, Department of Neurology, BSMMU, Dhaka

3. Resident, Department of Neurology, BSMMU, Dhaka. 
increasing popularity in endoscopic over microscopic procedures ${ }^{6}$.

Technological advances in the areas of endoscopeassisted microneurosurgery, frameless stereotaxy and three-dimensional computer-assisted neuronavigation, color Doppler ultrasonography and real-time intraoperative magnetic resonance imaging have been applied to the classic transsphenoidal operation.

\section{Methods:}

It was a prospective cross sectional study. Sampling technique was purposive consecutive. Total 25 cases of pituitary adenoma by transphenoidal microscopic approach and 12 cases were done by endonasal endoscopic approach from January 2010 to December 2014 at the Department of Neurosurgery, Bangababdhu Sheikh Mujib Medical University, Dhaka. Patients with pituitary adenoma who had visual impairment and hormonal imbalance requiring surgery for it and who had post-operative histological confirmation of pituitary adenoma were included in this study. Exclusion criteria are patients who had concomitant intra-ocular disease making visual assessment difficult, systemic disorders other than pituitary adenoma that affected visual function, presence of any other intracranial pathology. Data were collected pre-designed data collection sheet.
Data were analysis using computer based programme statistical package for social science (SPSS) for windows version 20.

\section{Operation procedure:}

Under general anaesthesia with supine position head is raised slightly from body. Nose was parallel to the floor, head was $20^{\circ}$ flexed and rotated to left shoulder, surgeon will stand towards the right shoulder. Disinfectant was used providone iodine soaked gauze. Killian type nasal speculum and Hardy nasal speculum were used. The middle turbinate was identified and passage was make between the narrow space of middle turbinate and nasal septum. Ostium of sphenoidal air sinus and choana were identified.

Bilaterally nasal mucosa was dissected. Hadat flap were made those who were operated by endoscopic approach. Keel of the vomer was identified and was removed. Anterior wall of sphenoidal air sinus, sinus cavity, sinus mucosa and posterior wall of sphenoidal air sinus was removed. Dura was opened after coagulation and tumour was excised by suction ring currete and micro ronger. Seller floor was reconstructed and nasal pack was given with ribbon gauze and merocele.

Results:

Table-I

Sex distribution of patients by sex

\begin{tabular}{lcccccc}
\hline Sex & \multicolumn{2}{c}{ Endoscopic group $(\mathrm{n}=12)$} & & \multicolumn{2}{c}{ Microscopic group $(\mathrm{n}=25)$} & P value \\
\cline { 2 - 3 } & No & $\%$ & & No & $\%$ & \\
\hline Male & 8 & 66.7 & & 16 & 64.0 & 0.873 \\
Female & 4 & 33.3 & & 9 & 36.0 & \\
\hline
\end{tabular}

Table-I shows male predominated than female.

Table-II

Distribution of the patients by age

\begin{tabular}{lcccccc}
\hline Age & \multicolumn{2}{c}{ Endoscopic group $(\mathrm{n}=12)$} & & \multicolumn{2}{c}{ Microscopic group $(\mathrm{n}=25)$} & P value \\
\cline { 2 - 3 } & No & $\%$ & & No & $\%$ & \\
\hline$<20$ & 1 & 8.3 & & 1 & 4.0 & 0.547 \\
$21-39$ & 4 & 33.3 & & 4 & 16.0 & \\
$40-59$ & 5 & 41.6 & & 16 & 64.0 & \\
$\geq 60$ & 2 & 16.6 & & 4 & 16.0 & \\
\hline
\end{tabular}

It was evident that $40-59$ years age group belongs to the highest group. 
Table-III

Distribution of patients by the size

\begin{tabular}{lcccccc}
\hline Size & \multicolumn{2}{l}{ Endoscopic group $(\mathrm{n}=12)$} & & \multicolumn{2}{c}{ Microscopic group $(\mathrm{n}=25)$} & P value \\
\cline { 2 - 3 } & No & $\%$ & & No & $\%$ & \\
\hline Microadenoma & 2 & 16.6 & & 7 & 28.0 & 0.329 \\
Macroadenoma & 10 & 83.3 & & 18 & 72.0 & \\
\hline
\end{tabular}

It was documented that macroadenema occupied 83.37 in endoscopic group \& $72 \%$ in microscopic group.

Table-IV

Distribution patients by visual disturbance

\begin{tabular}{|c|c|c|c|c|c|}
\hline \multirow[t]{2}{*}{ Sex } & \multicolumn{2}{|c|}{ Endoscopic group $(n=12)$} & \multicolumn{2}{|c|}{ Microscopic group $(n=25)$} & \multirow[t]{2}{*}{ P value } \\
\hline & No & $\%$ & No & $\%$ & \\
\hline Normal vision & 1 & 8.3 & 2 & 8.0 & 0.876 \\
\hline $\begin{array}{l}\text { Blind of only one eye } \\
\text { with temporal } \\
\text { hemianopia other eye }\end{array}$ & 4 & 33.3 & 5 & 20.0 & \\
\hline Bilateral papiloedema & 1 & 8.3 & 1 & 4.0 & \\
\hline Complete blindness & 3 & 24.9 & 5 & 20.0 & \\
\hline Bitemporal haemianopia & 2 & 16.6 & 7 & 28.0 & \\
\hline Bilateral hand movement only & 1 & 8.3 & 5 & 20. & \\
\hline
\end{tabular}

Table-V

Distribution of patients with pituitary apoplexy

\begin{tabular}{lcccccc}
\hline & \multicolumn{2}{l}{ Endoscopic group $(\mathrm{n}=12)$} & & \multicolumn{2}{c}{ Microscopic group $(\mathrm{n}=25)$} & P value \\
\cline { 2 - 3 } & No & $\%$ & & No & $\%$ & \\
\hline Present & 1 & 8.3 & & 3 & 12.0 & 0.7366 \\
Absent & 11 & 91.3 & & 22 & 88.0 & \\
\hline
\end{tabular}

Pituitary apoplexy was present $8.3 \%$ in endoscopic group \& 12.8 in microscopic group.

Table-VI

Distribution of patients by functional types of tumour

\begin{tabular}{lcccccc}
\hline & \multicolumn{2}{c}{ Endoscopic group $(\mathrm{n}=12)$} & & \multicolumn{2}{c}{ Microscopic group $(\mathrm{n}=25)$} & P value \\
\cline { 2 - 3 } & No & $\%$ & & No & $\%$ & \\
\hline Non functional tumourn & 3 & 24.9 & & 7 & 28.0 & 0.944 \\
Acromegally & 3 & 24.9 & & 7 & 28.0 & \\
Giantism & 0 & 00 & & 1 & 4.0 & \\
Prolactinoma & 5 & 41.7 & & 8 & 32.0 & \\
Cortisol secreting tumour & 1 & & 8.3 & 2 & 8.0 \\
\hline
\end{tabular}

Majority of tumor were prolactinoma in (endoscopic had group 41.71 and microscopic group had 32.6\%). 
Table-VII

Distribution of the patients by excision of tumour

\begin{tabular}{lcccccc}
\hline & \multicolumn{2}{c}{ Endoscopic group $(\mathrm{n}=12)$} & & \multicolumn{2}{c}{ Microscopic group $(\mathrm{n}=25)$} & P value \\
\cline { 2 - 3 } & No & $\%$ & & No & $\%$ & \\
\hline Total resection & 9 & 75.0 & & 14 & 56.0 & 0.474 \\
Subtotal resection & 2 & 16.6 & & 9 & 36.0 & \\
Partial resection & 1 & 8.3 & & 2 & 8.0 & \\
\hline
\end{tabular}

Table VII showed $75 \%$ tumors were excised totally (endoscopically \& $56 \%$ tumors were excised microscopically).

Table-VIII

Distribution of the patients by postoperative complication

\begin{tabular}{lcccccc}
\hline & \multicolumn{2}{c}{ Endoscopic group $(\mathrm{n}=12)$} & & \multicolumn{2}{c}{ Microscopic group $(\mathrm{n}=25)$} & P value \\
\cline { 2 - 3 } & No & $\%$ & & No & $\%$ & 0.808 \\
Diabetes insipidus & 5 & 41.6 & & 14 & 52.0 & \\
Cerebral salt wasting & 2 & 16.6 & & 4 & 12.0 & \\
CSF leakage & 1 & 8.3 & & 3 & 12.0 & \\
Pnemocephalus & 0 & 00 & & 1 & 4.0 & \\
Intracerebral & 0 & 00 & & 1 & 4.0 & \\
haemorrhage & & & & & 4.0 & \\
SIADH & 0 & 00 & & 1 & 4.0 & \\
Meningitis & 0 & 00 & & 1 & 4.0 & \\
Septal perforation & 0 & 00 & & 1 &
\end{tabular}

Table VIII showed different complications after surgery (i.e. endoscopic and microscopic groups).

Table-IX

Distribution of patients by postoperative outcome of tumour

\begin{tabular}{|c|c|c|c|c|c|}
\hline & \multicolumn{2}{|c|}{ Endoscopic group $(\mathrm{n}=12)$} & \multicolumn{2}{|c|}{ Microscopic group $(\mathrm{n}=25)$} & \multirow[t]{2}{*}{$P$ value } \\
\hline & No & $\%$ & No & $\%$ & \\
\hline \multicolumn{6}{|l|}{ Visual status } \\
\hline Improved & 10 & 83.3 & 16 & 64.0 & 0.159 \\
\hline Same as before & 1 & 8.3 & 7 & 28.0 & \\
\hline Deterioration & 1 & 8.3 & 2 & 8.0 & \\
\hline Hormonal status & & & & & \\
\hline Improved & 6 & 50 & 12 & 48 & 0.835 \\
\hline Same as before & 5 & 41.8 & 12 & 48 & \\
\hline Deterioration & 1 & 8.3 & 1 & 4 & \\
\hline
\end{tabular}

The table IX showed that $83.3 \%$ patient's visual status had imrpved endoscopic surgery \& $64 \%$ had improved microscopic surgery. 


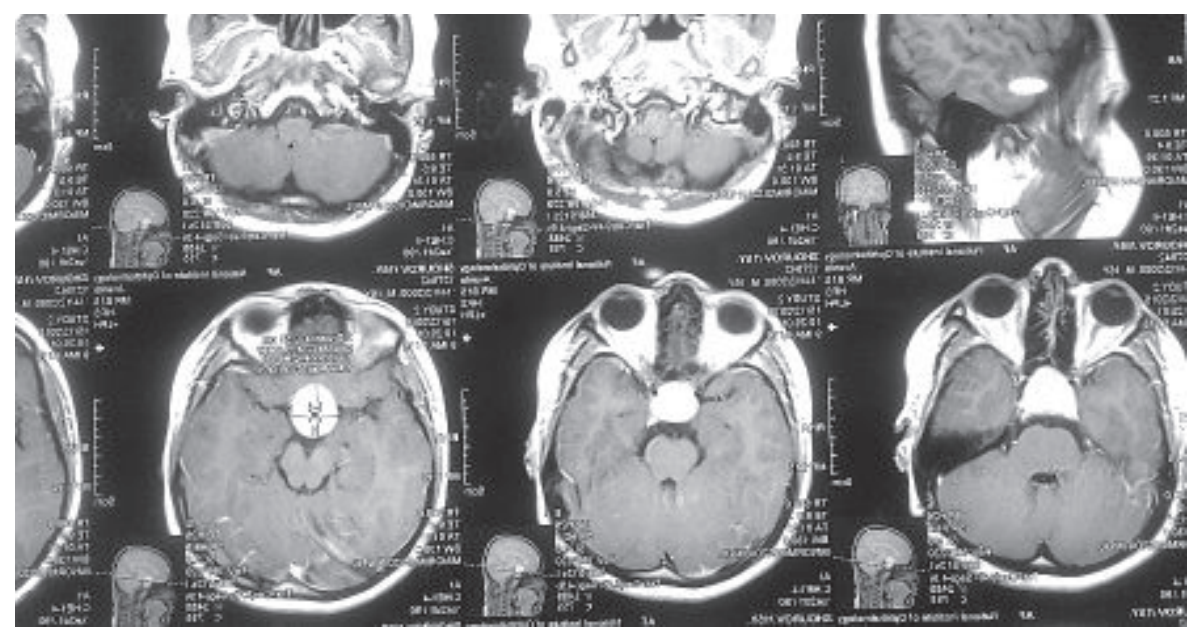

Fig. 1: Preoperative MRI show macroadenoma (Axial)

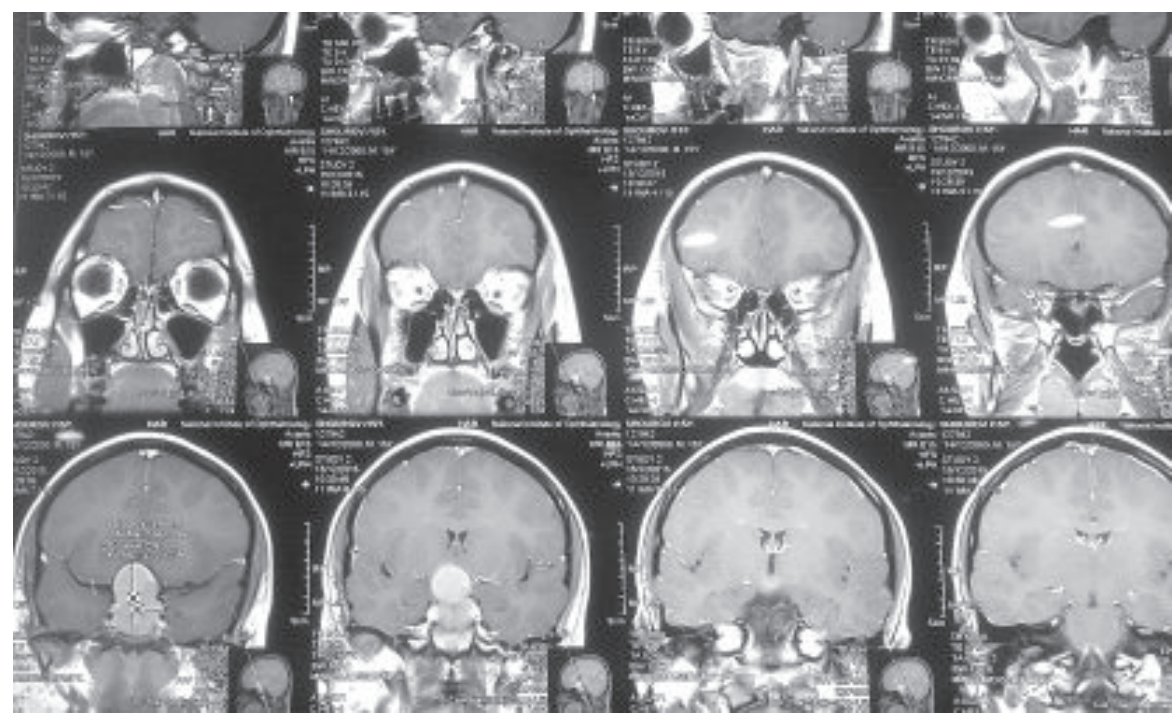

Fig. 2: Preoperative MRI show macroadenoma (Coronal)

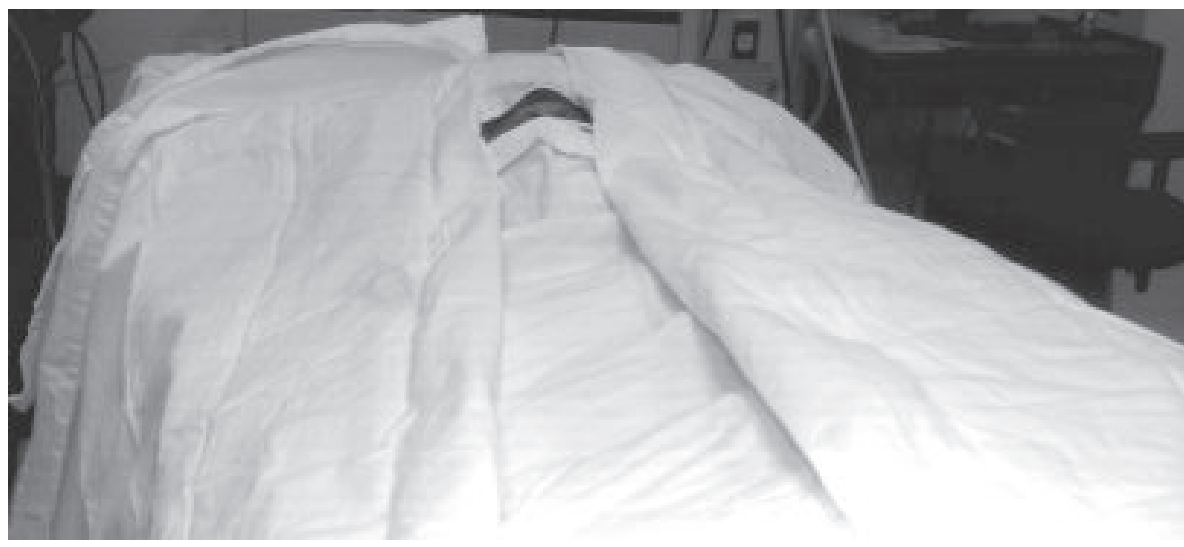

Fig. 3: Peroperative photograph after drapping of the patient 

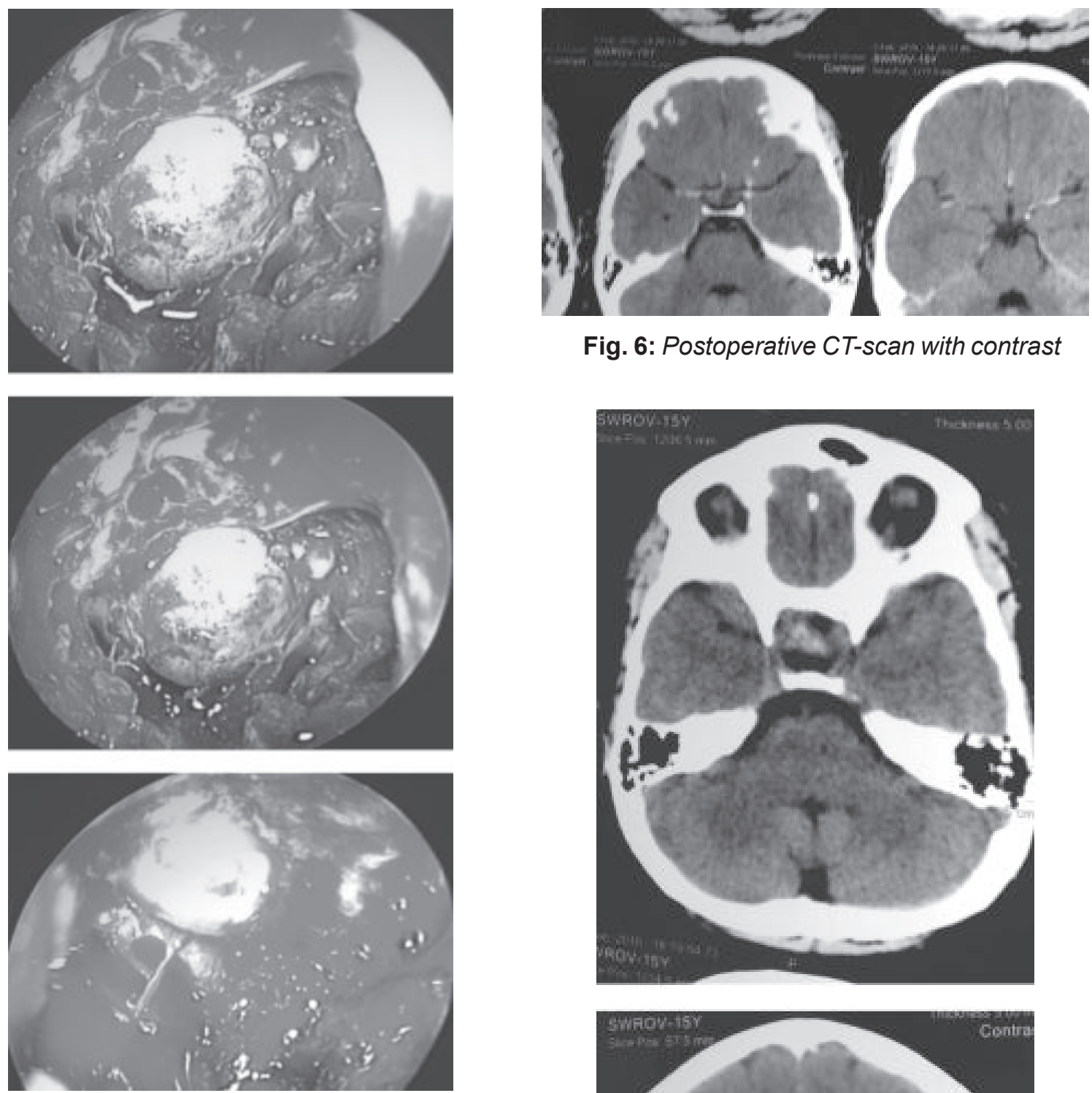

Fig. 4: Endoscopic preoperative photograph of the tumour in different view

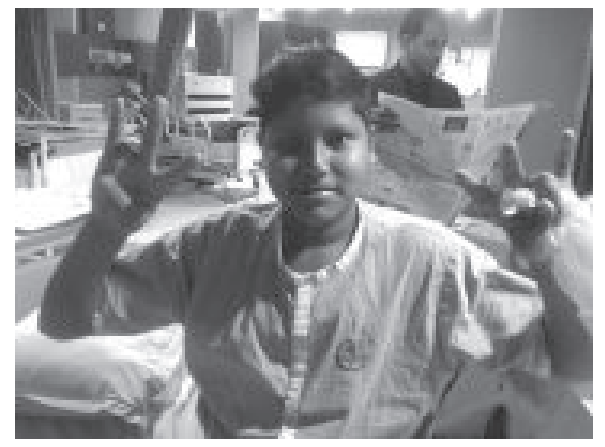

Fig. 5: Postoperative photograph

Fig. 6: Postoperative CT-scan with contrast
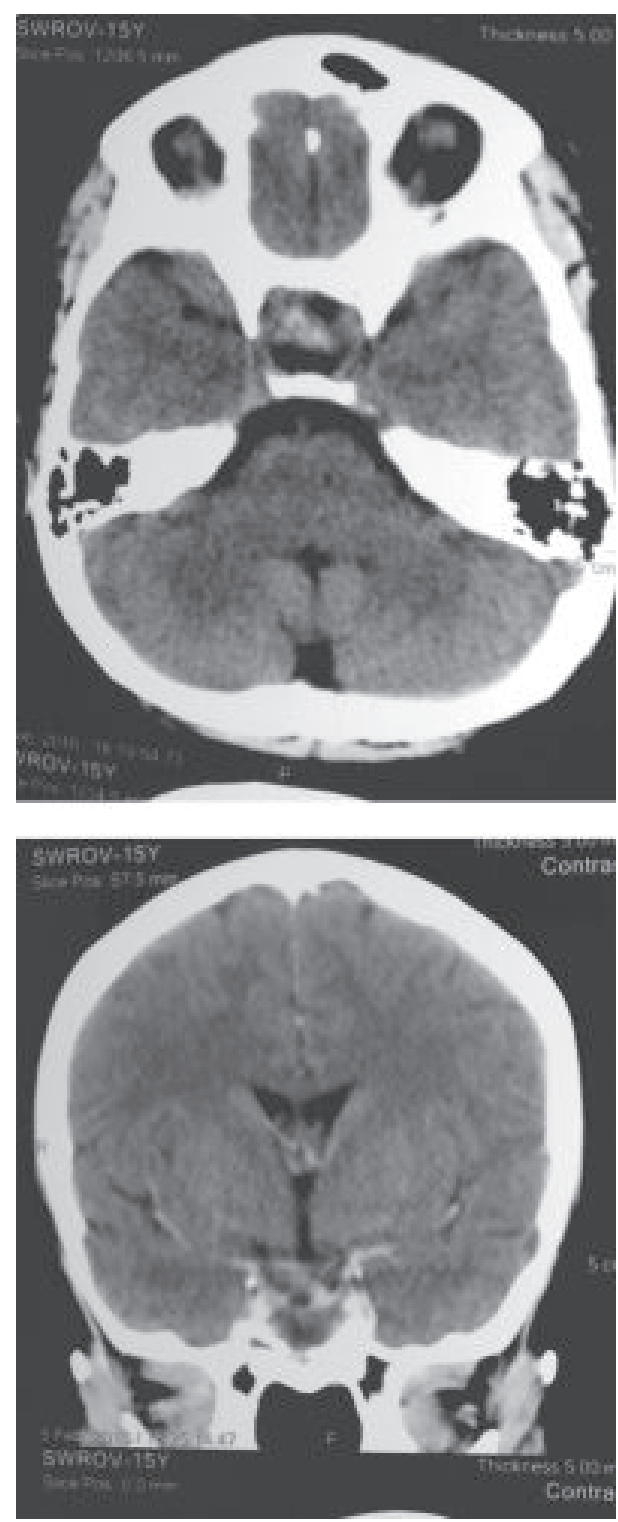

Fig. 7: Peroperative view 


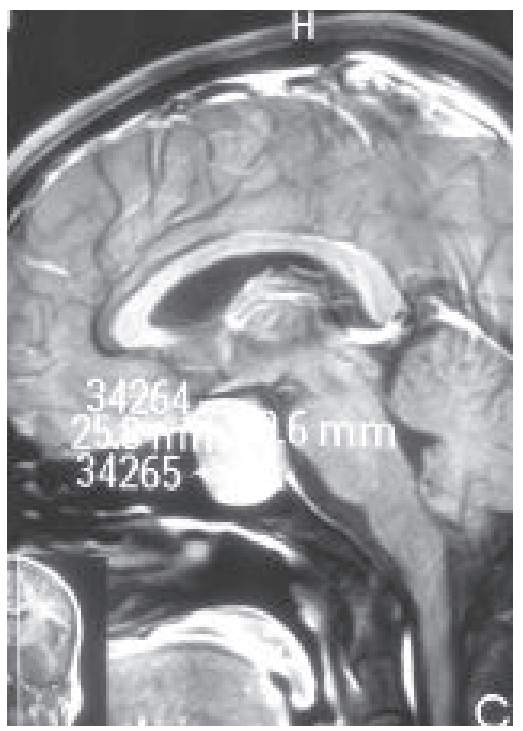

Fig. 8: Postoperative CT-scan with contrast in different view

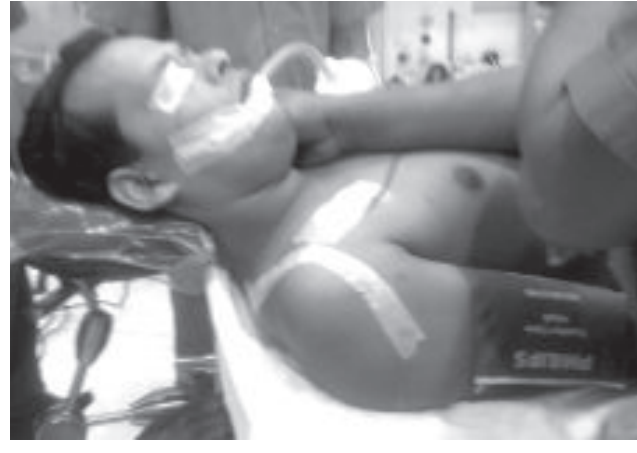

Fig.-9: Preoperative view

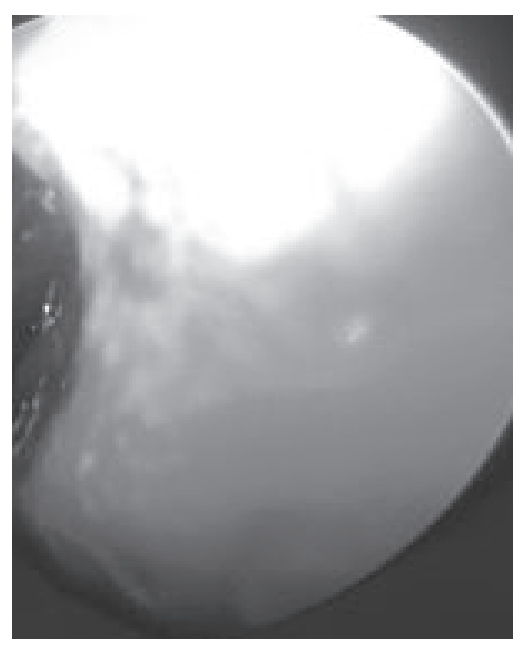

Fig.-11: Endoscopic different view of tumour
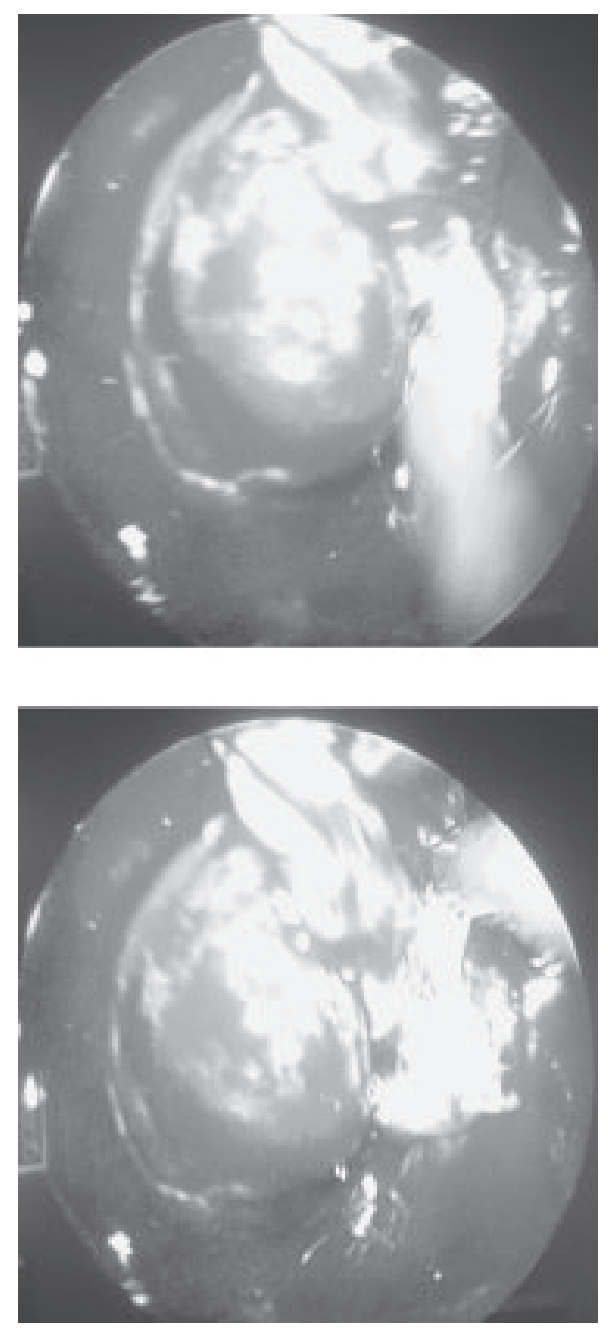

Fig.-10: Endoscopic different view of tumour

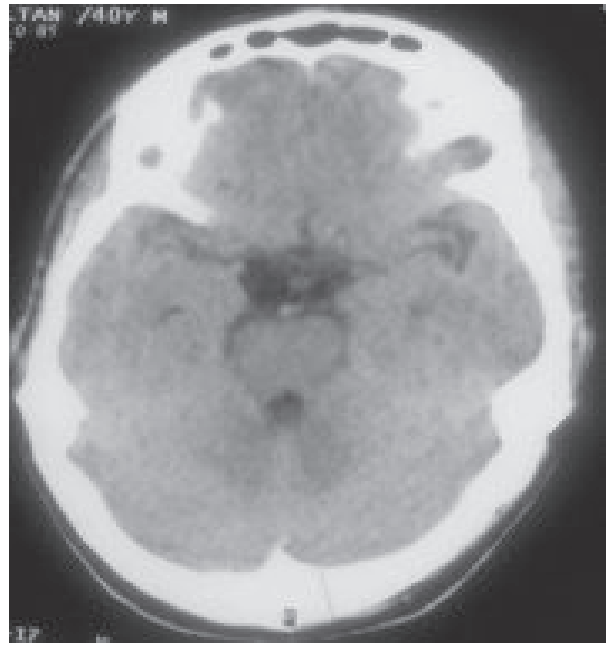

Fig.-12: Postoperative CT scan of brain 


\section{Discussion:}

Over the last century, pituitary adenoma surgery has evolved from a craniotomy approach toward less invasive approaches. In the past twenty years, there is growing evidence to support the use of endoscopic techniques as an alternative approach in the treatment of pituitary adenomas ${ }^{6-11}$.

Several authors have discussed the potential outcomes of the endoscopic technique. DeKlotz et al. ${ }^{8}$ used a meta-analysis to reveal the superior rate of gross total resection (GTR) (79\% versus $65 \%, P<0.0001)$ as well as the lower rates of CSF leak $(5 \%$ versus $7 \%, P<0.01)$, septal perforation $(0 \%$ versus $5 \%$ ) for the endoscopic approach compared with the sublabial approach. Rotenberg et al. ${ }^{9}$ concluded that the two approaches had similar outcomes (GTR, hormonal abnormality resolution) but that the endoscopic approach was associated with fewer complications as well as a shorter hospital stay and length of operation. Goudakos et al. ${ }^{10}$ demonstrated that the rates of GTR/CSF leakage were similar between the two techniques. However, other study also revealed a lower incidence of post-operative DI and a shorter hospital stay in the studied endoscopic groups ${ }^{12}$. Other systematic reviews also support the safety and short-term efficacy of endoscopic pituitary surgery ${ }^{6,10}$. Interestingly, Ammirati et al. ${ }^{13}$ recently reported a meta-analysis concluding that endoscopic removal of pituitary adenoma, in the short term, does not seem to confer any advantages over the microscopic technique and the incidence of vascular complications was higher with endoscopic than with microscopic removal of pituitary adenomas. In our study showed CSF leakage $1(8.3 \%)$ in endoscpic approach and $3(12 \%)$ in microscopic approach. Diabetes insipidus was 5(41.6\%) in (table-VIII) edoscopic approach and 14(56\%) was in microscopic approach. In endoscopic approach penumocphalus and intracerebral haemorrhage were none but in microscopic approach these complication were only in $1(4 \%)$.

The primary explanation is that most of the previous reports pertain to single-armed studies in the absence of a reliable comparison. Second, the inclusion and exclusion criteria are key factors in each study, which may lead to different conclusions. In addition, the complication rate in microscopebased surgery is already low and the rates of GTR are high. Demonstrating a statistically significant difference between endoscopic and microscopic techniques will require a larger number of cases. In our study total removal of tumour by endoscopic approach were $9(75 \%)$ and microscopically total removal were done 14(56\%) (Fig. 1-10).

The results of previous study were clearly favor the endoscopic approach for pituitary surgery over the microscopic approach. The endoscopic approach yielded a significantly improved rate of gross total removal (GTR) with lower rate of post-operative septal perforation. It is important to recognize that the above analysis represents only the results of early outcomes and complications. There are few publication long-term studies following these patients beyond the initial post-operative period. This study shows complication more in microscopic approach than endoscopic approach.

\section{Conclusions:}

In conclusion, the results of our study support the safety and effectiveness of endoscopic transsphenoidal pituitary adenoma surgery is more than tranphenoidal microscopic approach. Future studies with a long-term follow-up are required to determine the outcomes and complications of endoscopic pituitary surgery.

\section{Reference:}

1. Ezzat S, Asa SL, Couldwell WT, Barr CE, Dodge WE,VanceML, et al.: The prevalence of pituitary adenomas: a systematicreview. Cancer 2004;101:613-19.

2. Schloffer $\mathrm{H}$ : Erfolgreiche Operation eines Hypophysentumors auf nasalem Wege. Wien Klin Wchnschr, 1907;20:621-24.

3. Cushing $\mathrm{H}$ : The Weir Mitchell Lecture: Surgical experiences with pituitary disorders. JAm Med Assoc., 2014;63:1515-25.

4. Zada G, Kelly DF, Cohan P, et al.: Endonasal transsphenoidal approach for pituitary adenomas and other sellar lesions: an assessment of efficacy, safety, and patient impressions. J Neurosurg., 2003;98:350-358.

5. Bushe KA, Halves E: Modifizierte Technik bei transnasaler Operation der Hypophysengeschwulste. ActaNeurochir, 1978;41:163-75.

6. Jane JA Jr, Han J, Prevedello DM, Jagannathan J, Dumont AS, Laws ER Jr: Perspectives on 
endoscopic transsphenoidal surgery. Neurosurg Focus, 2005;19(6):E2.

7. Razak AA, Horridge M, Connolly DJ, Warren DJ, Mirza S, Muraleedharan V, Sinha S. Comparison of endoscopic and microscopic transsphenoidal pituitary surgery: early results in a single centre. $\mathrm{Br} \mathrm{J}$ Neurosurg. 2013; 27:40-43.

8. DeKlotz TR, Chia SH, Lu W, Makambi KH, Aulisi E, Deeb Z. Meta-analysis of endoscopic versus sublabial pituitary surgery. Laryngoscope. 2012;122:511-18.

9. Rotenberg B, Tam S, Ryu WH, Duggal N. Microscopic versus endoscopic pituitary surgery: a systematic review. Laryngoscope. 2010;120:1292-97.

10. Goudakos JK, Markou KD, Georgalas C. Endoscopic versus microscopic trans- sphenoidal pituitary surgery: a systematic review and meta-analysis. Clin Otolaryngol. 2011;36:212-220.

11. Tabaee A, Anand VK, Barron Y, Hiltzik DH, Brown SM, Kacker A, Mazumdar M, Schwartz TH. Endoscopic pituitary surgery: a systematic review and meta-analysis. J Neurosurg. 2009;111:545-54.

12. Shah S, Har-El G. Diabetes insipidus after pituitary surgery:incidence after traditional versus endoscopic transsphenoidal approaches. Am J Rhinol. 2001;15:377-79.

13. Ammirati M, Wei L, Ciric I. Short-term outcome of endoscopic versus microscopic pituitary adenoma surgery: a systematic review and meta-analysis. J Neurol Neurosurg Psychiatry. 2013;84:843-49. 